\title{
Geosynthetic Subgrade Stabilization - Field Testing and Design Method Calibration
}

\section{Authors: Eli V. Cuelho and Steve W. Perkins}

NOTICE: this is the author's version of a work that was accepted for publication in Transportation Geotechnics. Changes resulting from the publishing process, such as peer review, editing, corrections, structural formatting, and other quality control mechanisms may not be reflected in this document. Changes may have been made to this work since it was submitted for publication. A definitive version was subsequently published in Transportation Geotechnics [VOL\# 10 (March 2017)] DOI: $10.1016 /$ j.trgeo.2016.10.002

Cuelho, Eli V., and Steve W. Perkins. "Geosynthetic Subgrade Stabilization - Field Testing and Design Method Calibration." Transportation Geotechnics 10 (March 2017): 22-34. doi:10.1016/ j.trgeo.2016.10.002.

Made available through Montana State University's ScholarWorks scholarworks. montana.edu 


\title{
Geosynthetic subgrade stabilization - Field testing and design method calibration
}

\author{
E.V. Cuelho ${ }^{\mathrm{a}, *}$, S.W. Perkins ${ }^{\mathrm{b}}$ \\ ${ }^{a}$ Western Transportation Institute, Montana State University, PO Box 174250, Bozeman, MT 59717, USA \\ ${ }^{\mathrm{b}}$ Montana State University, 205 Cobleigh Hall, Bozeman, MT 59717, USA
}

\begin{abstract}
Geogrids and geotextiles are used routinely to stabilize weak subgrade soils during road construction. Typical subgrade stabilization applications are temporary haul roads or unpaved low-volume roads, but can also include paved roads built on poorer foundation materials. Full-scale test sections were constructed, trafficked and monitored to compare the relative operational performance of geosynthetics used as subgrade stabilization, as well as determine which material properties were most related to performance. Unpaved test sections were constructed using twelve geosynthetics consisting of a variety of geogrids and geotextiles. Multiple control test sections were also built to evaluate the effect that subgrade strength, base course thickness, and/or presence of the geosynthetic had on performance. Even though the geotextile materials used during this study showed good performance as subgrade stabilization, material properties associated with their performance was difficult to establish due to the limited number of test sections and lack of relevant tests to properly characterize these types of materials for this application. Using longitudinal rut as the primary indicator of performance, it was determined through a linear regression analysis that the stiffness of the geogrid junctions in the cross-machine direction correlated best with performance in this application and under these conditions. Using this knowledge, the design equation associated with the Giroud-Han method was calibrated to make geogrid junction stiffness in the cross-machine direction the primary property of the geosynthetic, thereby replacing geogrid aperture stability modulus. The calibration and verification of this method is described herein.
\end{abstract}

\section{Background and introduction}

For low-volume roadways and temporary construction platforms where excavation and replacement of inferior subsoils may not be cost effective, soil stabilization using geosynthetics may provide a working platform so that the base course aggregate layer can be properly constructed and overall rutting reduced. Geosynthetics are planar polymeric materials that have been extensively used in these situations (i.e., subgrade stabilization) to reinforce and/or separate poorer naturally deposited soils from the crushed aggregate layer. The separation function is primarily attributed to geotextiles, while the reinforcement function may be derived from both geotextiles and geogrids; however, in certain circumstances, geogrids may also offer separation (Maxwell et al., 2005). Subgrade stabilization is typically applicable for unpaved temporary roads such as haul roads, or construction platforms to support permanent roads. These roads are generally characterized by low volumes of heavy vehicles that can tolerate 
deeper ruts. According to the National Highway Institute, geosynthetic stabilization techniques used for these types of roads are "one of the more important uses of geosynthetics" (Holtz et al., 2008). Historically, geotextiles were first used in these applications; however, geogrids are more commonly used in recent years. The first design for geotextile stabilization of unpaved roads was created in the late 1970s by Steward et al. (1977) based on soil mechanics theory and experimental data generated in the laboratory and field. Since then, several alternative designs for geogrid stabilization have also been created (Tingle and Webster, 2003; Giroud and Han, 2004a; USCOE, 2003). Limitations within each of these methods, lack of calibration for a wide variety of products, and a growing variety of the types, strengths, and composition of geosynthetic reinforcement products has introduced uncertainty in the design of geosynthetic-reinforced unpaved roads.

Geosynthetics can improve the performance of weak subgrades under temporary unpaved roads by the following mechanisms: (1) reduction of plastic shear stresses that cause bearing capacity failure in the subgrade, (2) reduction of maximum normal stresses on the subgrade surface by improved load distribution, (3) increase in the bearing capacity of the subgrade by confining lateral movement at the subgrade-base interface and a reorientation of the induced shear stresses, (4) increase in the bearing capacity and stress reduction attributable to the "tensioned membrane effect" in rutted areas, (5) lateral restraint and reinforcement of base course aggregates, and (6) reduction of mixing between subgrade and base soils (Hufenus et al., 2006; Maxwell et al., 2005; Giroud and Han, 2004a; Leng, 2002; Perkins et al., 2005; Watn et al., 2005). Three of these mechanisms are illustrated in Fig. 1. These improvements in subgrade performance can facilitate compaction, reduce the gravel surface thickness, delay rut formation, and extend the service life of unpaved roads, particularly in cases of very soft subgrades with a California Bearing Ratio (CBR) less than three (Benson et al., 2005; Hufenus et al., 2006).

The current practice of using geosynthetics for subgrade stabilization is primarily based on empirical evidence from constructed test sections. Field tests constructed strictly for research purposes, instead of during scheduled rehabilitation or reconstruction activities, offer better control over study variables such as careful preparation of soil and reduced incidental trafficking. Despite this, it is still difficult to achieve uniform conditions throughout a project site utilizing the natural subgrade (e.g., Fannin and

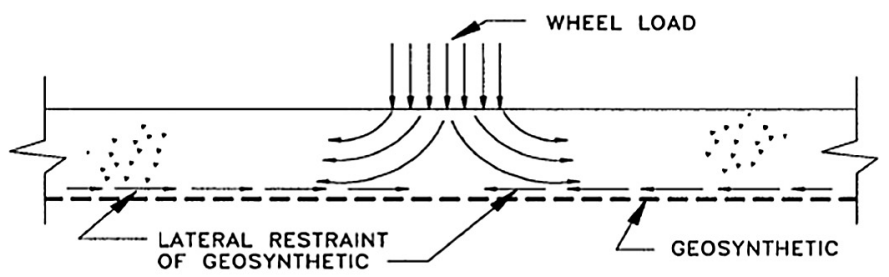

(a) LATERAL RESTRAINT

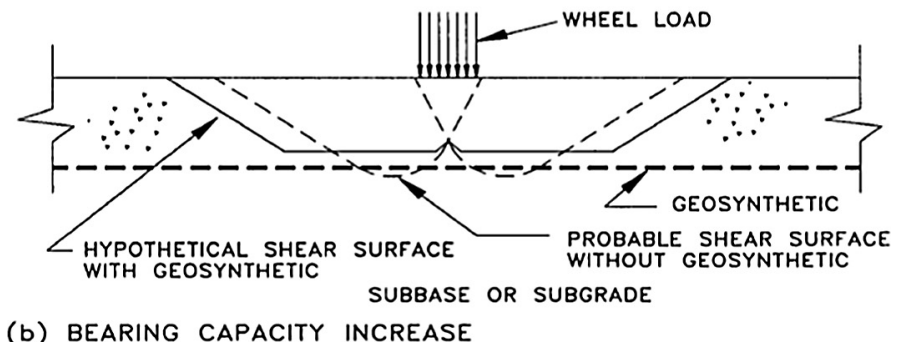

(b) BEARING CAPACITY INCREASE

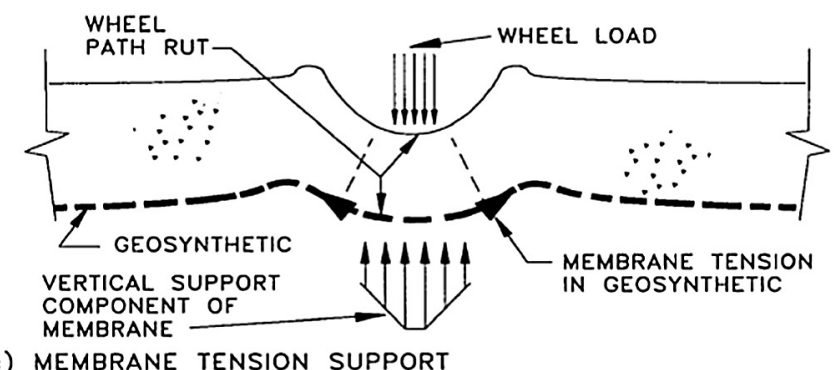

Fig. 1. Possible reinforcement functions provided by geosynthetics in subgrade stabilization applications (from Haliburton et al. (1981)). 
Sigurdsson, 1996; Edil et al., 2002; and Hufenus et al., 2006). Conversely, research studies in which a subgrade soil was artificially placed demonstrate better consistency (e.g., Santoni et al., 2001; Perkins, 2002; Tingle and Webster, 2003; Cuelho and Perkins, 2009; Cuelho et al., 2014).

While laboratory studies can be conducted more quickly and usually include more alternatives, they are only able to simulate field conditions and, as Hufenus et al. (2006) point out, there "are no incontrovertible indications from laboratory tests of the influence that the geosynthetic will have on the performance of the pavement under trafficking" (p. 23). Thus, the need still exists for field tests that provide uniform conditions and incorporate a variety of geosynthetics in order to develop a sufficient database of performance results. The need for such a database of information is resoundingly clear in light of the fact that there is still not a universally accepted and calibrated design method for unpaved roads (or construction platforms) that incorporate both soil and geosynthetic material properties.

A simple existing design method published by the Federal Highway Administration (Holtz et al., 2008) is based on the U.S. Forest Service method developed by Steward et al. (1977). A more recent design method for unpaved roads that attempts to incorporate geosynthetic properties was theoretically derived based on the stresses that develop at the base-subgrade interface. The impact of these stresses and the subgrade bearing capacity were related to rut depth based on empirical data (Giroud and Han, 2004a). However, only limited data were used to calibrate the model: (1) field data from Hammitt et al. (1970) for unreinforced unpaved sections, and (2) lab data from Gabr (2001) that involved two versions of one type of geosynthetic (integrally formed geogrid). One parameter (the bearing capacity, $N_{c}$ ) in the model can take on three different values depending on whether the roadway is (1) unreinforced, (2) geotextile reinforced, or (3) geogrid reinforced design. If a geogrid is under consideration, the aperture stability modulus is used, but only if the material property is within the approximate range of the types of geogrids tested by Gabr (2001) for which the model was calibrated. Even though this design method was intended to be used to design reinforced and unreinforced unpaved roads, there are inherent limitations in how it models the contribution of various geosynthetics that should be considered. While this model is an improvement over less sophisticated designs from the 1980s (Giroud and Noiray, 1981 and Giroud et al., 1985), there is still a need to investigate the performance of geosynthetics in controlled field tests. Calibrations with additional data sets may be sufficient, although geosynthetic material properties other than aperture stability modulus should be considered.

Based on these limitations, two ambitious projects were sponsored by the Montana Department of Transportation (MDT) to evaluate the performance and behavior of a wide variety of geogrids and geotextiles when used as subgrade stabilization (Cuelho and Perkins, 2009 - Phase I; Cuelho et al., 2014 - Phase II). The primary objective of these research efforts was developed based on deficiencies in the standard design techniques and lack of agreement as to which geosynthetic properties are most relevant for this application. The results of this research were used to understand which properties are most relevant to this application, and consequently to update the design methodology to incorporate these material properties. The result of which should be a more accurate design method that more broadly encompasses materials with which good experience exists.

\section{Experimental program}

This research project was specifically planned to quantify differences in performance of various geosynthetic products under the same conditions (i.e., same subgrade strength and base course thickness). In addition, supplemental test sections were constructed to study the effect that variations in subgrade strength and base course thickness had on the performance. Specifically, three control sections (i.e., no geosynthetic) were constructed, each having different thickness of base course aggregate, and three test sections were built using the same integrally-formed geogrid (test sections IFG-1, IFG-2, and IFG-3), each having different subgrade strengths. The final arrangement of the test sections is shown in Fig. 2, which includes the average subgrade strengths and base thicknesses. Each test section was $4.9 \mathrm{~m}$ wide and $15 \mathrm{~m}$ long. The Transcend research test facility managed by the Western Transportation Institute at Montana State University was used for this study.

Twelve geosynthetic products (ten geogrids and two geotextiles) were used in this research project to evaluate their relative performance under the conditions presented herein. A summary of the basic material characteristics and strengths of these products is listed in Table 1, and corresponding photos are provided in Fig. 3. Five laboratory tests were used to characterize the geosynthetics used in this research, and include wide-width tensile strength (ASTM D4595 and ASTM D6637), cyclic tensile modulus (ASTM D7556), resilient interface shear stiffness (ASTM D7499), junction strength (ASTM D7737), and aperture stability modulus (Kinney, 2000). Results from tests conducted in the cross-machine direction are summarized in Table 2.

Geosynthetic tensile strength is commonly used to evaluate the ability of the geosynthetic to transmit load, specifically in its principal strength directions, which generally lines up with the machine and cross-machine directions of the material. This material property also allows designers to ensure it has adequate strength to sustain construction stresses. Working stresses in roadway applications generally correspond to less than 5 percent strength. The cyclic tensile modulus, $J$, is a material property that is derived from a recently developed test procedure that describes the tensile properties of the geosynthetic under cyclic loading representative of pavement reinforcement applications. Similarly, the resilient interface shear modulus, $G_{I}$, describes the stiffness of the interface between the geosynthetic and surrounding aggregates under small cyclic loads and at various levels of load and confinement. The junction strength, $X j$, is the average shear strength of the geogrid junctions (or nodes) 


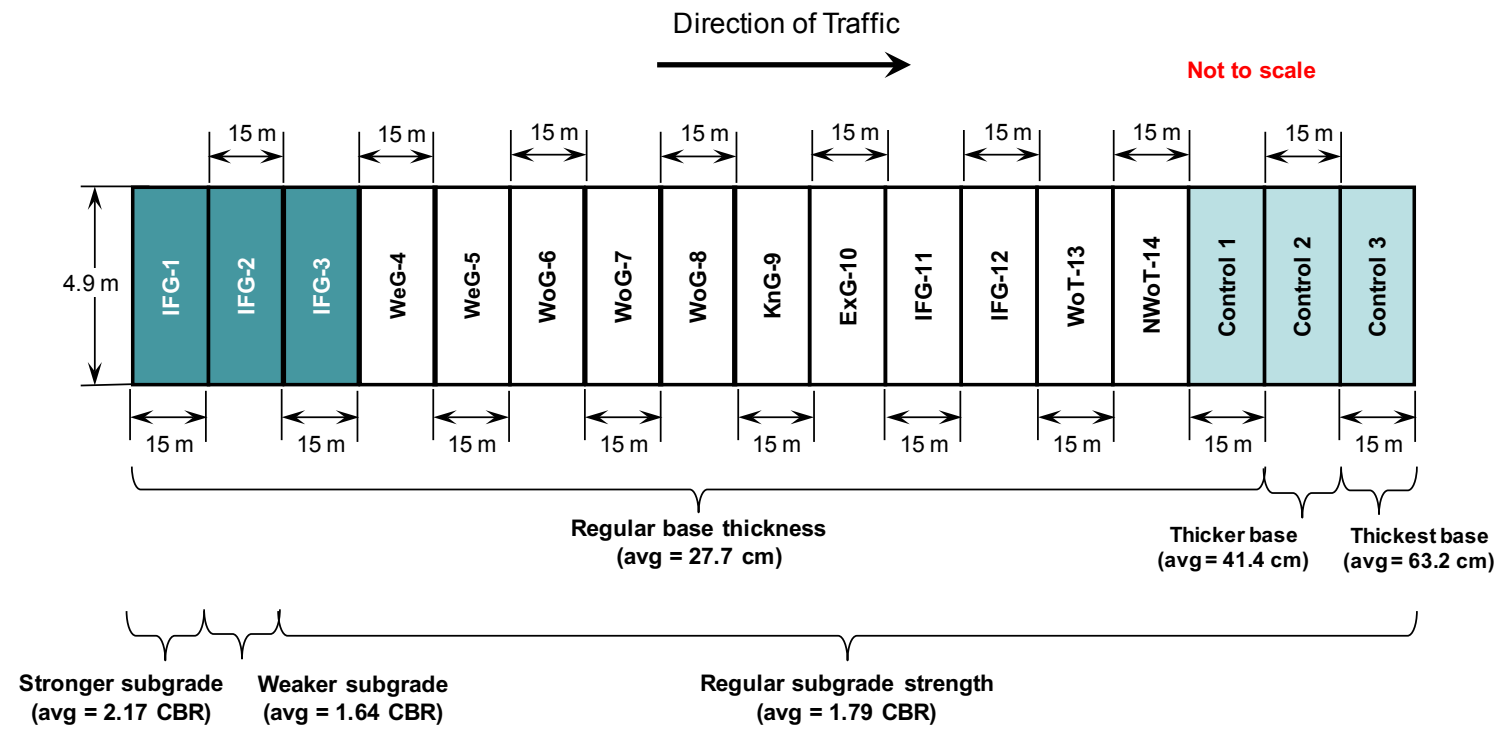

Fig. 2. General layout of test sections.

Table 1

Summary of geosynthetic characteristics.

\begin{tabular}{|c|c|c|c|c|c|c|c|c|c|}
\hline \multirow[t]{2}{*}{$\begin{array}{l}\text { Geosynthetic } \\
\text { Test Section }\end{array}$} & \multirow[t]{2}{*}{ Polymer and structure ${ }^{\mathrm{b}}$} & \multirow[t]{2}{*}{$\begin{array}{l}\text { Mass per unit } \\
\text { area }\left(\mathrm{g} / \mathrm{m}^{2}\right)\end{array}$} & \multirow{2}{*}{$\begin{array}{l}\text { Aperture } \\
\text { Size (mm) } \\
\text { MD x XMD }\end{array}$} & \multicolumn{2}{|c|}{$\begin{array}{l}\text { Strength @ } \\
2 \%(\mathrm{kN} / \mathrm{m})\end{array}$} & \multicolumn{2}{|c|}{$\begin{array}{l}\text { Strength@ } \\
5 \%(\mathrm{kN} / \mathrm{m}) \\
\end{array}$} & \multicolumn{2}{|c|}{$\begin{array}{l}\text { Ultimate } \\
\text { Strength }(\mathrm{kN} / \mathrm{m})\end{array}$} \\
\hline & & & & MD & XMD & MD & XMD & MD & XMD \\
\hline $\begin{array}{l}\text { IFG-1, IFG-2 } \\
\text { and IFG-3 }\end{array}$ & PP - integrally-formed, biaxial geogrid & 302 & $25 \times 33$ & 8.5 & 12.0 & 15.7 & 21.8 & 21.6 & 28.4 \\
\hline WeG-4 & PP - vibratory-welded, biaxial geogrid & 200 & $33 \times 33$ & 14.1 & 13.8 & 26.4 & 26.7 & 30.4 & 39.6 \\
\hline WeG-5 & PP - biaxial, welded geogrid & 203 & $43 \times 41$ & 14.6 & 12.5 & 29.6 & 25.9 & 38.6 & 34.7 \\
\hline WoG-6 & PMY - PVC-coated, woven, biaxial geogrid & 322 & $25 \times 25$ & 5.8 & 9.0 & 10.0 & 13.5 & $29.8^{\mathrm{f}}$ & $55.2^{\mathrm{f}}$ \\
\hline WoG-7 & PMY - PVC-coated, woven, biaxial geogrid & 417 & $25 \times 25$ & 5.8 & 14.4 & 10.4 & 21.1 & $31.3^{f}$ & $84.9^{f}$ \\
\hline WoG-8 & PMY - PVC-coated, woven, biaxial geogrid & 309 & $25 \times 25$ & 9.4 & 10.8 & 20.1 & 18.7 & 38.4 & 47.0 \\
\hline KnG-9 & PP - polymer-coated, knitted, biaxial geogrid & 220 & $15 \times 15$ & 9.7 & 13.8 & 20.8 & 28.3 & 27.2 & 38.2 \\
\hline ExG-10 $10^{g}$ & PP - extruded, triple-layer, biaxial geogrid & 329 & $43 \times 51^{\mathrm{c}}$ & 8.3 & 10.1 & 15.3 & 19.6 & 20.6 & 32.8 \\
\hline IFG-11 & PP - integrally-formed, triaxial geogrid & 180 & $41 \times 41^{\mathrm{d}}$ & $0.5^{\mathrm{h}}$ & 4.7 & $2.6^{\mathrm{h}}$ & 9.7 & $9.1^{\mathrm{h}}$ & 12.3 \\
\hline IFG-12 & PP - integrally-formed, triaxial geogrid & 217 & $41 \times 41^{\mathrm{d}}$ & $1.0^{\mathrm{h}}$ & 5.7 & $3.8^{\mathrm{h}}$ & 10.9 & $11.0^{\mathrm{h}}$ & 12.9 \\
\hline WoT-13 & PPF - woven geotextile & 417 & $40^{\mathrm{e}}$ & 7.3 & 21.9 & 18.8 & 50.2 & 82.0 & 89.2 \\
\hline NWoT-14 & PP - non-woven, needle-punched geotextile & 271 & $80^{\mathrm{e}}$ & - & - & - & - & $1.03^{\mathrm{i}}$ & $1.13^{\mathrm{i}}$ \\
\hline
\end{tabular}

$\mathrm{MD}=$ machine direction; $\mathrm{XMD}=$ cross-machine direction.

a Acronym meanings (related to manufacturing process): IFG = integrally-formed grid, WeG = welded grid, WoG $=$ woven grid, KnG = knitted grid,

ExG = extruded grid, WoT = woven textile, NWoT = non-woven textile; numbers represent position of test section.

b $\mathrm{PP}=$ polypropylene, $\mathrm{PMY}=$ polyester multifilament yarn, $\mathrm{PPF}=$ polypropylene fiber.

c for a single layer; apparent opening size is reduced when three layers are stacked on top of one another.

d reported as "rib pitch" in manufacturer's specification sheet.

e Apparent Opening Size (AOS) in U.S. Standard sieve size, ASTM D4751.

f WoG-6 and WoG-7 materials experienced some grip slippage at their ultimate strength values.

$\mathrm{g}$ Tested as a composite, i.e., not separately (triple layer material).

h When the IFG-11 and IFG-12 geogrids are tested in the machine direction, tensile members are offset by 30 degrees from the direction of the applied load, resulting in large distortions of the material and lower and/or inaccurate strength values.

${ }^{\mathrm{i}}$ Grab tensile strength (ASTM D4632) in kN.

per unit width. Strength values are averaged from multiple tests on a single tensile member that is pulled from its junction with a cross-member. Junction stiffness $X j_{\alpha}$ was determined by taking the secant stiffness of the junction strength response at $1.3 \mathrm{~mm}$ of displacement. Finally, the aperture stability modulus, ASM, describes the dimensional stiffness or torsional rigidity of geogrids under a rotational load. The torque it takes to rotate the material with respect to the clamp is called the aperture stability modulus, reported in units of $\mathrm{N}-\mathrm{m} / \mathrm{deg}$. 

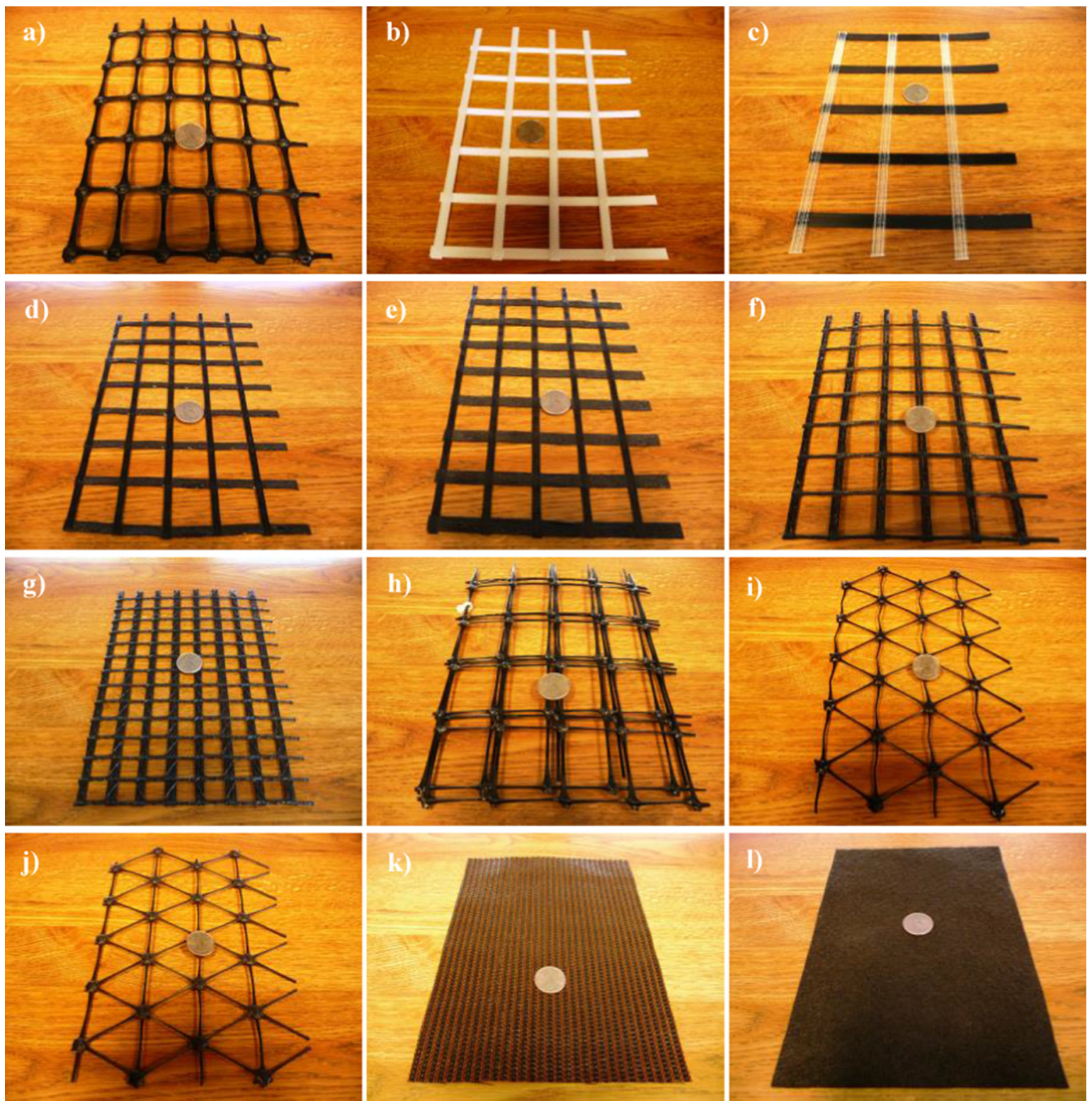

Fig. 3. Photos of geosynthetics: (a) IFG-1, IFG-2 and IFG-3, (b) WeG-4, (c) WeG-5, (d) WoG-6, (e) WoG-7, (f) WoG-8, (g) KnG-9, (h) ExG-10, (i) IFG-11, (j) IFG12, (k) WoT-13, and (l) NWoT-14.

The soil used to construct the subgrade consisted of natural overburden material that classified as CL (sandy lean clay) according to the USCS classification system (ASTM D2487). The base course material for this project consisted of crushed aggregates and classified as GP-GC (poorly graded gravel with clay with sand) according to the USCS classification system (ASTM D2487). It contained 10 percent fines and 55 percent fractured faces. Laboratory strength tests run on the base course aggregate (ASTM D1883) resulted in a California Bearing Ratio (CBR) value greater than 100; however, in-field CBR tests indicated that the average in-place CBR strength of the base was approximately 20 . This difference is due primarily to the conditions under which the base course was tested in the lab compared to how these values were obtained in the field. The laboratory CBR test uses a rigid cylinder to confine the sample, and due to the particle size of this particular gradation, a replacement was necessary to reduce the size of the larger particles. This replacement had a large effect on the strength. In addition, the bearing capacity at higher penetration $(5 \mathrm{~mm})$ were greater than at $2.5 \mathrm{~mm}$ penetration, so the higher values are what are recommended to be reported by the standard. Finally, the shape of the bearing capacity curve was concave upward making it necessary to apply a correction, which further increased the value. The CBR of the base course in the field was 
Table 2

Geosynthetic material properties in the cross-machine direction used in the analysis.

\begin{tabular}{|c|c|c|c|c|c|c|c|c|c|c|}
\hline \multirow[t]{2}{*}{ Geosynthetic test section $^{a}$} & \multicolumn{6}{|c|}{$J_{\text {cyclic }}(\mathrm{kN} / \mathrm{m})$} & \multirow[t]{2}{*}{$G_{I}(\mathrm{MPa})$} & \multirow[t]{2}{*}{$X j(\mathrm{kN} / \mathrm{m})$} & \multirow[t]{2}{*}{$X j_{\alpha}(\mathrm{MN} / \mathrm{m} / \mathrm{m})$} & \multirow[t]{2}{*}{$A S M(\mathrm{~N}-\mathrm{m} / \mathrm{deg})$} \\
\hline & $0.5 \%$ & $1.0 \%$ & $1.5 \%$ & $2.0 \%$ & $3.0 \%$ & $4.0 \%$ & & & & \\
\hline IFG-1, IFG-2 and IFG-3 & 933 & 918 & 915 & 911 & 913 & 965 & 2106 & 30.1 & 4.36 & 0.78 \\
\hline WeG-4 & 1150 & 1141 & 1148 & 1157 & 1213 & 1297 & 1284 & 10.1 & 4.43 & 1.15 \\
\hline WeG-5 & 1019 & 983 & 971 & 1005 & 1034 & 1091 & 631 & 8.7 & 3.43 & 1.57 \\
\hline WoG-6 & 765 & 794 & 823 & 839 & 900 & 983 & 1227 & 6.5 & 2.17 & 0.25 \\
\hline WoG-7 & 1231 & 1252 & 1290 & 1325 & 1421 & 1552 & 2013 & 5.0 & 1.74 & 0.27 \\
\hline WoG-8 & 919 & 913 & 941 & 971 & 1070 & 1174 & 1657 & 6.3 & 3.57 & 0.35 \\
\hline KnG-9 & 1064 & 1061 & 1063 & 1103 & 1160 & 1136 & 890 & 1.8 & 0.68 & 1.09 \\
\hline ExG-10 & 855 & 806 & 810 & 794 & 790 & 808 & 1308 & $\mathrm{NA}^{\mathrm{c}}$ & $\mathrm{NA}^{\mathrm{c}}$ & $\mathrm{NA}^{\mathrm{c}}$ \\
\hline IFG-11 & 320 & 374 & 398 & 412 & 412 & 426 & 609 & 12.7 & 2.18 & 0.28 \\
\hline IFG-12 & 424 & 443 & 448 & 454 & 470 & 464 & 1671 & 13.1 & 1.37 & 0.55 \\
\hline WoT-13 & 1647 & 2120 & 2258 & 2285 & 2344 & 2407 & 2269 & NA & NA & NA \\
\hline NWoT-14 & $\mathrm{NT}^{\mathrm{b}}$ & $\mathrm{NT}^{\mathrm{b}}$ & $\mathrm{NT}^{\mathrm{b}}$ & $\mathrm{NT}^{\mathrm{b}}$ & $\mathrm{NT}^{\mathrm{b}}$ & $\mathrm{NT}^{\mathrm{b}}$ & 1013 & NA & NA & NA \\
\hline
\end{tabular}

NT $=$ not tested.

$\mathrm{NA}=$ not applicable.

a Acronym meanings (related to manufacturing process): IFG = integrally-formed grid, WeG= welded grid, WoG $=$ woven grid, KnG = knitted grid,

ExG $=$ extruded grid, WoT $=$ woven textile, NWoT $=$ non-woven textile; numbers represent position of test section .

b Material too delicate to test using unconfined cyclic tension.

c Impossible to test with triple layer construction.

determined using a dynamic cone penetrometer, the mechanics of which differs significantly from the laboratory method.

Construction of the test sections began with preparing and placing the subgrade (depicted in Fig. 4), followed by installing the geosynthetics and instrumentation, and finally preparing and placing the base course aggregate. A cross-sectional view of a typical test section is shown in Fig. 5 with the test vehicle. Preparation and construction of the subgrade and base course was monitored extensively to ensure that these materials were placed in a consistent and uniform manner.

The subgrade was built in six lifts that were approximately $15 \mathrm{~cm}$ deep for a total depth of about $0.9 \mathrm{~m}$. The subgrade was processed to reach the target strength by adding water from a water truck and fire hose. Water was added until it reached the target moisture content (target of approximately 23 percent to achieve $C B R=1.70$ ).

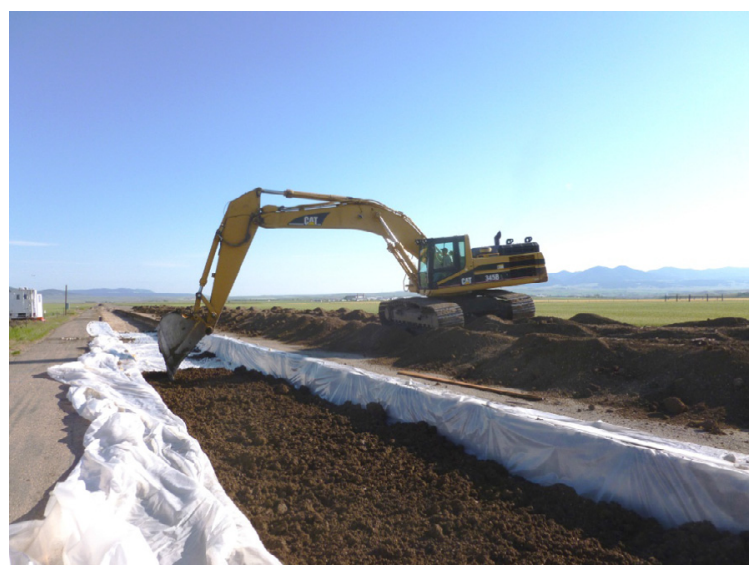

Fig. 4. Filling trench with prepared subgrade.
Processing was accomplished using a large excavator to move and mix the material as water was being added. Sufficient material was processed to construct a single $15-\mathrm{cm}$ deep layer over two test sections at a time (about $30 \mathrm{~m}^{3}$ of material). The subgrade was then placed in the trench using the excavator and a track-mounted skid-steer tractor was used to level and initially compact the subgrade. A smooth, single-drum, vibratory roller was used to compact the subgrade by making two passes of the roller in three longitudinal paths of the freshly placed subgrade. The moisture in the top surface of the subgrade was maintained during construction by periodically wetting the surface and keeping it covered with plastic until the next layer of subgrade or the base course could be placed. Prior to placement of the geosynthetics and base course, the top surface of the subgrade was smoothed and screeded to the height of the adjacent pavement surface. The final average strength of the subgrade in all the test sections was $C B R=1.79$.

Preparation of the base course aggregate began by adding water and mixing with an end loader until it reached optimum water content. A large screed that rested on the paved surface on both sides of the subgrade trench was used to level the surface of the gravel layer. The base course was placed in two layers. The final thickness of the first layer of base course was about $20 \mathrm{~cm}$ when compacted and the second was about $7.6 \mathrm{~cm}$ deep for a total of about $28 \mathrm{~cm}$ of gravel, on average. Two of the three control test sections contained thicker base material. The Control 2 test section was constructed of two layers of about $20 \mathrm{~cm}$ thick, for a total of about $40 \mathrm{~cm}$ of gravel when compacted, and the Control 3 test section was constructed of three layers of about $20 \mathrm{~cm}$ thick, and had a final average thickness of about $60 \mathrm{~cm}$ of gravel when compacted. Compaction was achieved using a smooth, single-drum, vibratory roller. In total, eight passes of the roller were made per lift. Assessment of the base course was evaluated using LWD, $\mathrm{DCP}$, in-field CBR and nuclear densometer tests. All of the test sections met the minimum 95 percent density 


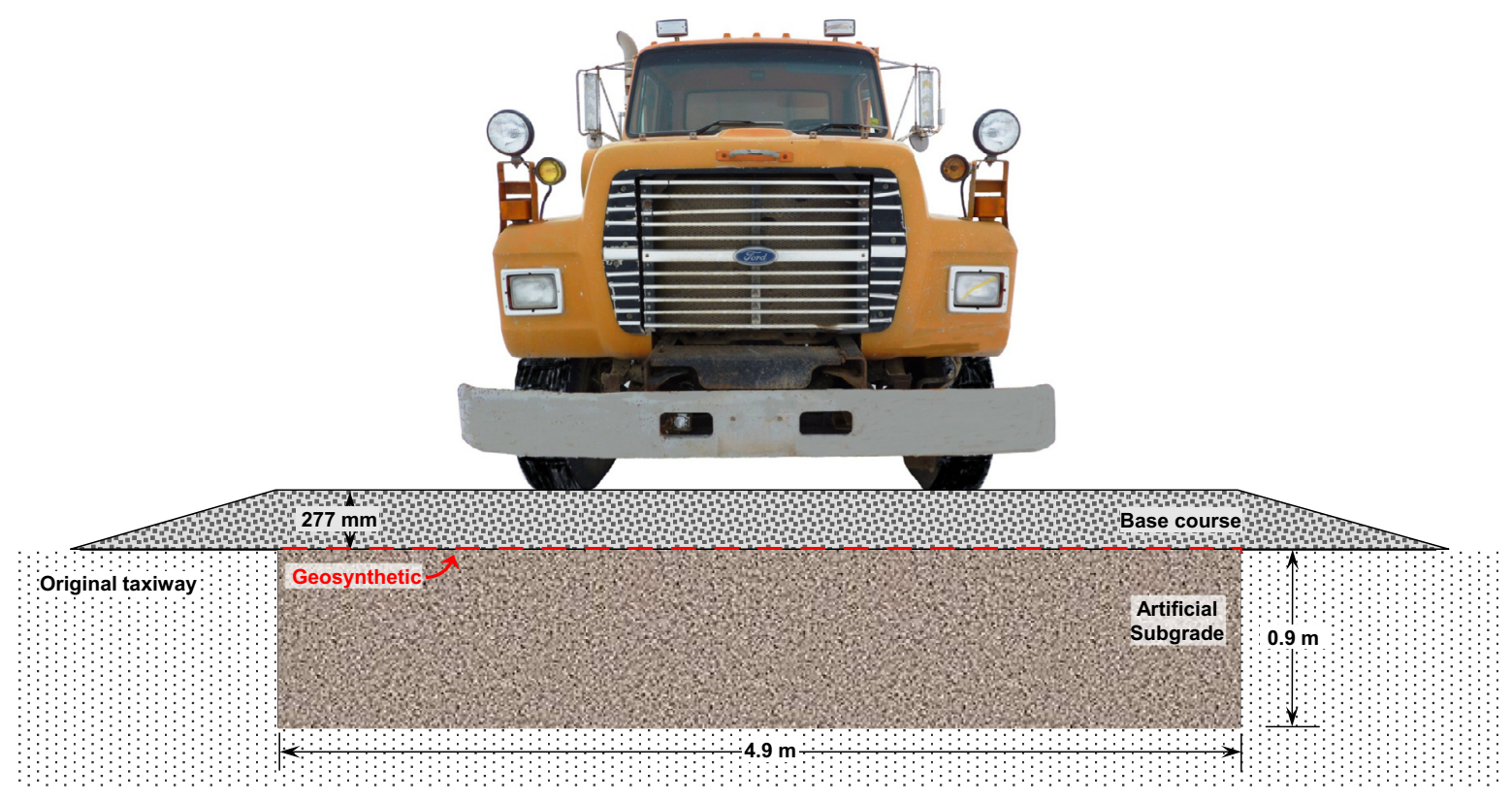

Fig. 5. Cross-sectional representation of typical test section (drawn to scale).

requirements based on Modified Proctor test results. A detailed summary and analysis of the physical attributes of the base course can be found in Cuelho et al. (2014).

Trafficking was accomplished using a three-axle dump truck that weighed 20.6 metric tons and had $620 \mathrm{kPa}$ tire pressure. Trafficking was always in one direction, and the speed was approximately $8 \mathrm{kph}$ to ensure that dynamic loads were not induced in the test sections from any unevenness in the gravel surface. Trafficking was applied until rut levels reached $75 \mathrm{~mm}$. Allowable ruts generally range from 50 to $100 \mathrm{~mm}$ for this application. Ruts greater than $75 \mathrm{~mm}$ may cause the undercarriage of the truck to drag during trafficking, especially if the subgrade experiences bearing capacity failure that results in heaving of the road surface. Photos of a typical test section during trafficking are presented in Fig. 6 for rut levels of about $0,25,50$ and $75 \mathrm{~mm}$, respectively. Once the allowable rut level was reached, repairs were made by placing additional gravel in the rutted areas. Repairs within test sections were made incrementally, so that unfailed portions of test sections could continue to be trafficked until they reached failure. No further measures of rut were made in areas that were repaired. Rut measurements were made at 1-meter intervals along two longitudinal lines (in the direction of traffic), corresponding to the outside rear wheels of the test vehicle. A robotic total station was used to make these measurements, and the data were used to determine rut as a function of the difference in the elevation of the measurement points over time.

\section{Data analysis}

Longitudinal rut measurements (in the direction of traffic) were the primary means used to determine the relative performance of each test section. Rut behavior was mainly affected by four factors: (1) the strength of the subgrade, (2) the depth of the base course, (3) the strength of the base course, and (4) the presence of the geosynthetic. The field test sections were constructed to have the same subgrade strength and base thickness (with the intentional exception of multiple control test sections) to minimize differences between test sections and facilitate a more direct comparison of their performance. Despite efforts during construction to eliminate differences in subgrade strength and base course thickness, small variations were inevitable. An empirical correction procedure was implemented to adjust the rut response for these two properties so that direct performance comparisons between test sections were more accurate. Rut data was not adjusted based on base course strength and stiffness because (1) strength and stiffness properties were not measured at every rut measurement point, and (2) there were no controls where these properties were purposefully varied to determine their effect on performance. After adjustments for subgrade strength and base course thickness were applied to the rut data, the remaining behavioral differences between the reinforced test sections could more confidently be attributed to the geosynthetic reinforcement.

Individual rut measurements were adjusted and averaged together within a particular test section. Individual values of rut greater than one standard deviation away from the mean were not used in the analysis. An analysis of the longitudinal rut responses was conducted to determine which geosynthetic material properties were most related to the performance of a particular test section. This analysis was conducted at various rut depths to determine whether different material properties affected performance at various levels of rut. Predicted values were used in the regression analysis for test sections that did not reach failure. The following material properties were considered in this analysis: 

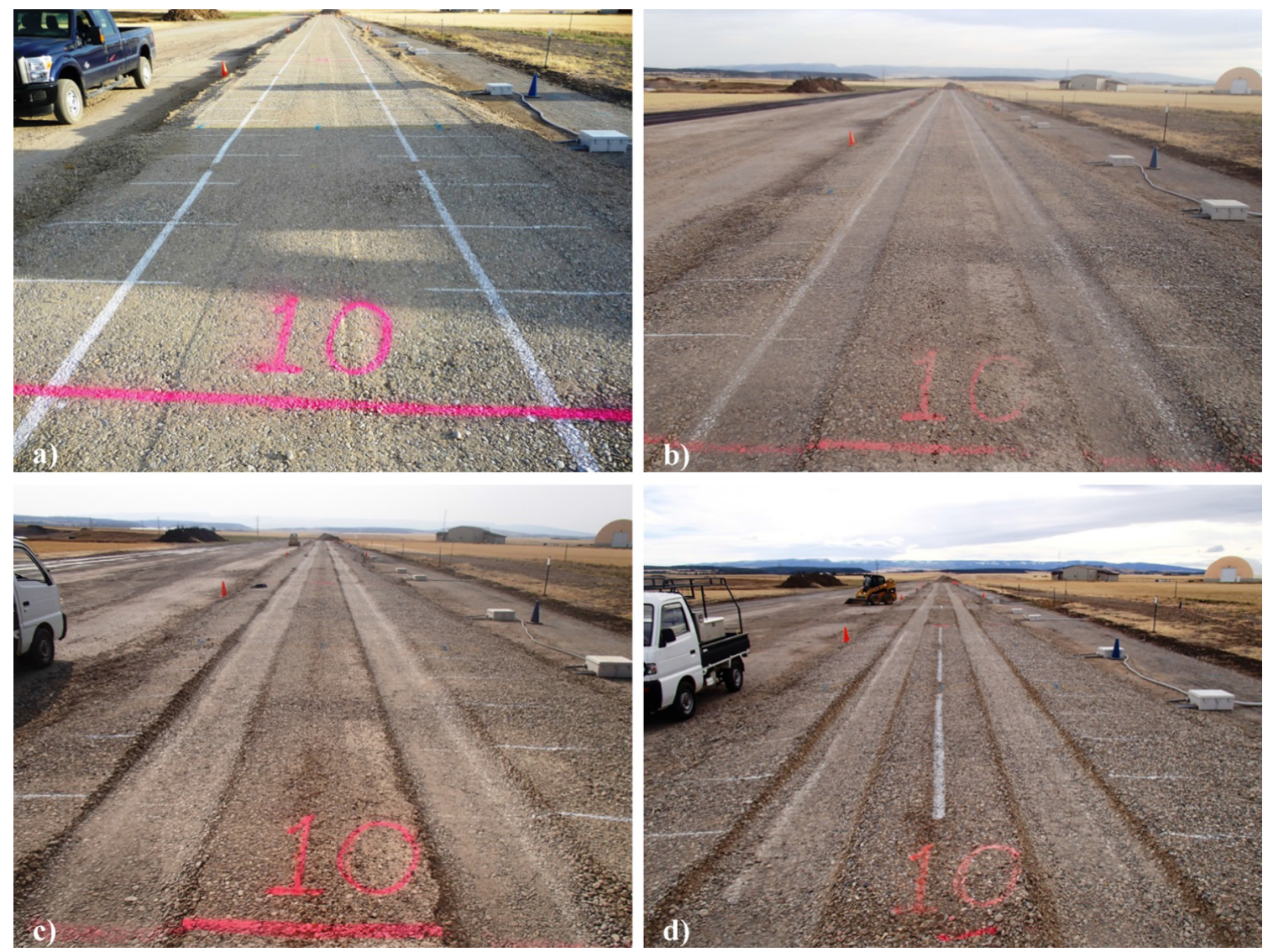

Fig. 6. Typical Phase II test section at (a) $0 \mathrm{~mm}$, (b) $25 \mathrm{~mm}$, (c) $50 \mathrm{~mm}$, and (d) $75 \mathrm{~mm}$ of rut.

- Wide-width tensile strength in the cross-machine direction at $2 \%$ (WWT-2\%).

- Wide-width tensile strength in the cross-machine direction at 5\% (WWT-5\%).

- Ultimate wide-width tensile strength in the crossmachine direction (WWT-Ult.).

- Cyclic tensile stiffness at 0.5, 1.0, 1.5, 2.0, 3.0 and 4.0 percent in the cross-machine direction (CTS- $0.5 \%$, CTS$1.0 \%$, CTS- $1.5 \%$, CTS- $2.0 \%$, CTS-3.0\%, CTS- $4.0 \%$ ).

- Resilient interface shear stiffness in the cross-machine direction (RISM).

- Junction strength in the cross-machine direction (Junc. Str.).

- Junction stiffness in the cross-machine direction, determined by taking the secant stiffness of the junction strength response at $1.3 \mathrm{~mm}$ of displacement (Junc. Stiff.)

- Aperture stability modulus (ASM).

Linear regression was used in this analysis because there were too few points to clearly indicate a more sophisticated regression equation, and it provided sufficient information to be able to compare data fit between individual factors or to observe changes or trends in data fit for multiple variables. In this analysis, the number of truck passes for a particular test section was adjusted by subtracting the number of truck passes in comparable control test sections to determine $N_{\text {add }}$, the number of additional truck passes a particular test section experienced in comparison to the unreinforced case. That allowed the $\mathrm{y}$-intercept to be set to zero because the absence of geosynthetic reinforcement would result in no benefit to the test section. R-squared (the coefficient of determination) is commonly used as the indicator of how well the data points fit the regression line, and was used in this analysis to determine how well a particular material property related to field performance. R-squared values approaching 1.0 indicate a better fit, while values less than that (including negative values) indicate poorer correlations. R-squared values greater than 0.5 were considered significant for the purposes of this analysis. The results from these analyses are shown in Fig. 7a (note: the analysis of some of the properties resulted in R-squared values less than zero, which are not shown).

Referring to Fig. 7a, the geosynthetic material property that best related to the performance of the test sections was the strength and stiffness of the junctions in the cross-machine direction, and this property correlated better with performance as rut increased. R-squared values in the machine direction (not shown) were all negative with the exception of the ultimate wide-width strength, which showed better correlation at lower levels of rut. A 

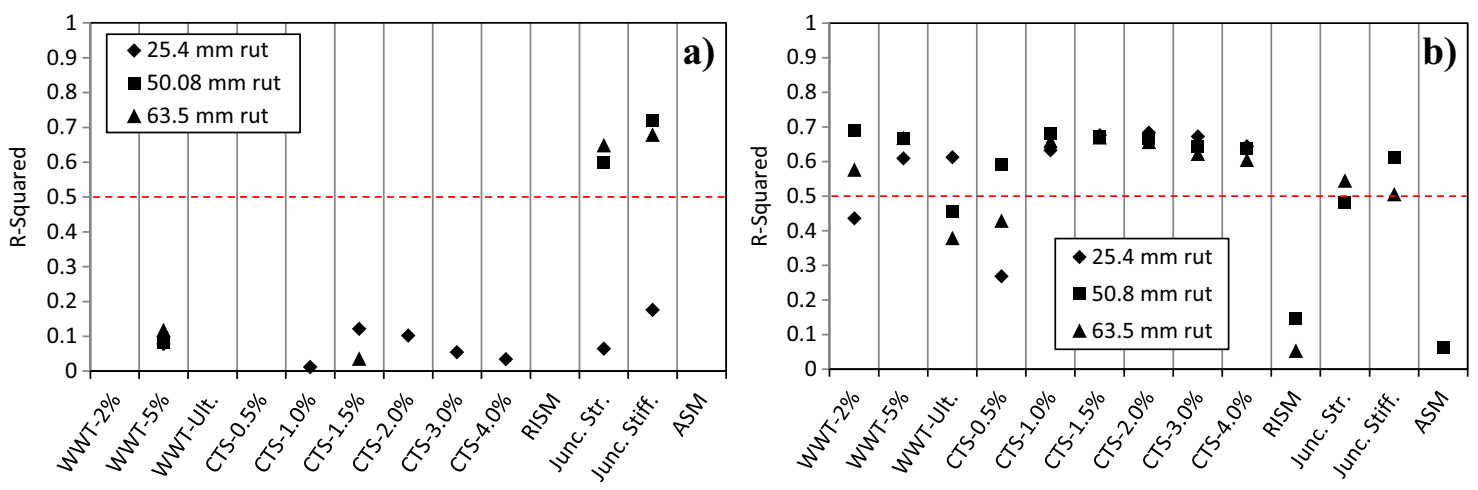

Fig. 7. Phase II regression analysis results in the cross-machine direction using (a) all data and (b) select data.

second linear regression analysis was conducted excluding data from geosynthetics that performed poorly (WoG-1 and $\mathrm{KnG}$ ) due to their low junction strengths. Knowing that the primary property linked to performance in these test sections was junction stiffness, these products were unable to transmit stresses into the cross-machine structural elements because the junctions were too weak. By eliminating these products from the analysis other potential links between the geosynthetic properties and performance became more apparent. The results of this analysis are shown in Fig. 7b. These results indicate that by excluding materials that did not perform well based on their weaker junctions, tensile strength in the material is also a good indicator of performance. This is most apparent in the wide-width tensile strengths at 5 percent and the cyclic stiffness values. R-squared values are reduced for junction strength and stiffness in this analysis because of the missing data.

A linear regression analysis was also conducted using rut data from an earlier phase of this project (Cuelho and Perkins, 2009 - Phase I). Six of the test sections from Phase I used the same geosynthetics as this project (IFG-3, WeG4, WeG-5, WoG-6, WoG-8, and NWoT-14). These test sections had very similar subgrade strengths but $75 \mathrm{~mm}$ less base aggregate thickness, creating a more severe condition than Phase II. Performance data was analyzed with respect to the material properties listed above at 25.4, 50.8, 76.2 and $101.6 \mathrm{~mm}$ of rut. The results of this analysis are shown in Fig. 8. Considering a similar approach as before, the regression analysis using performance data from Phase I indicates, overall, that tensile strength in both material directions relate to performance at higher levels of rut, while junction strength relates to performance at lower levels of rut. The relationship with junction stiffness peaks at $76.2 \mathrm{~mm}$ of rut. Aperture stability modulus is also related to early performance of the Phase I test sections.

Considering both phases of this effort, cross-machine junction stiffness and cross-machine tensile strength are the two most important properties associated with good performance of geogrids used in this application and under these conditions. These two properties work together to ensure proper reinforcement of the gravel layer and increased longevity of the road (evident as an increased number of load passes). Geogrids with weak junctions were unable to fully utilize the strength in the crossmachine direction because the load transfer through the individual members and into the junctions was weak. All of the materials in Phase I had adequate junction strength. Not surprisingly, a greater reliance on tensile strength was more evident in this case (refer to Fig. 8a). This information concurs with information from Phase II where tensile strength in the cross-machine direction was also linked to good performance (once materials with weak junctions were removed from the analysis, as shown in Fig. 7b). Overall, this analytical process helped establish geogrid material properties associated with good performance.

The geotextile materials used during these studies showed good performance as subgrade stabilization, but material properties associated with their performance were difficult to establish due to the limited number of test sections and lack of relevant tests to properly characterize these types of materials for this application. Understanding that junction stiffness in the cross-machine direction is the property of the geogrids that most related to their performance it can be inferred that the mechanism by which geotextiles provide reinforcement is related to how well they transmit stresses from one principal strength direction to the other. Despite that fact that fibers oriented orthogonally to one another are not firmly bound, the interaction between them is significantly enhanced by the overburden pressure of the road materials above them. The strong frictional bond between these fibers is able to transmit stresses from traffic loads into fibers oriented in the cross-machine direction, similar to a typical geogrid junction. Multiple fibers and intersections between these fibers means that there are significantly more paths for stresses to be transmitted. This helps explain why the geotextiles worked well in this application under these conditions. A similar case can be made for the non-woven geotextile. Its tensile properties are significantly enhanced by confinement from overburden, and the continuous sheetlike structure of the material creates an infinite number of stress paths.

\section{Calibration of the Giroud-Han Design equation}

Information from the testing program described above was used to calibrate the design equation associated with 

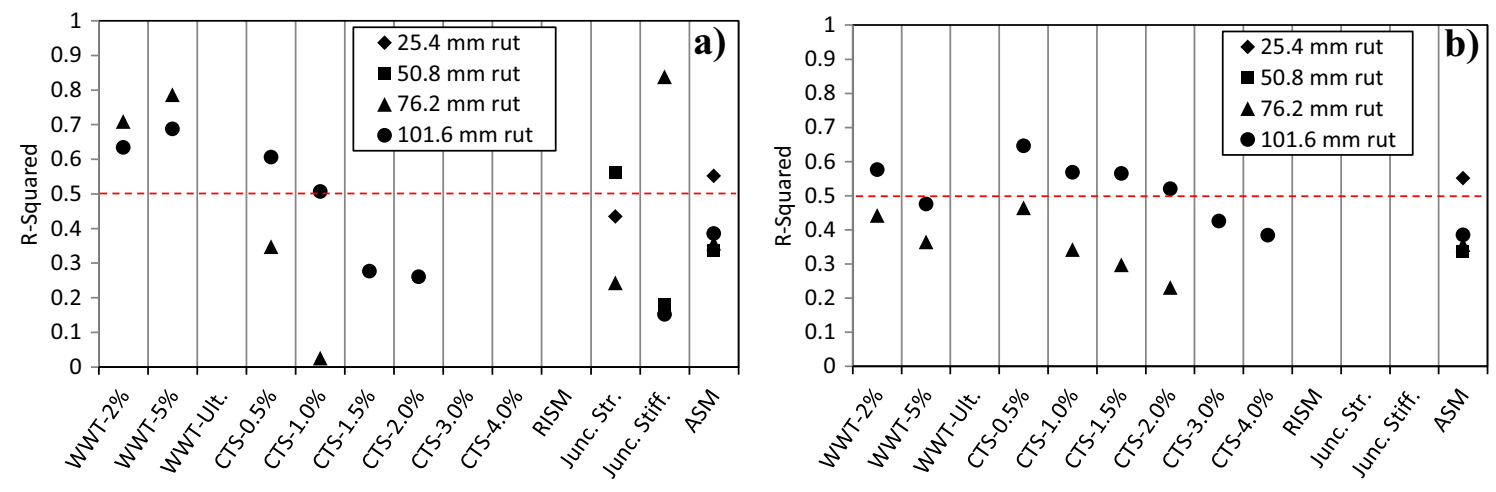

Fig. 8. Phase I regression analysis results using data from the (a) cross-machine direction and (b) machine direction.

the methodology developed by Giroud and Han (2004a,b). The generic design approach developed by Giroud and Han (also referred to as the G-H method) takes into consideration the geometry of the unpaved structure, the level of truck traffic, the truck axle configuration and loading, rut depth and serviceability, the properties of the base course and subgrade materials, the ratio of base course and subgrade strength, and the properties of the geogrid. The generic equation associated with the $\mathrm{G}-\mathrm{H}$ method is provided in Eq. (1).

$$
h=\frac{1+k \log N}{\tan \alpha_{0}\left[1+0.204\left(R_{E}-1\right)\right]}\left[\sqrt{\frac{\frac{p}{\pi r^{2}}}{\left(\frac{s}{f_{s}}\right)\left[1-\xi \exp \left(-\omega\left(\frac{r}{h}\right)^{n}\right)\right] N_{c} c_{u}}}-1\right] r
$$

where $h=$ compacted base course thickness $\{\mathrm{m}\}$. $N=$ number of axle passes. $k=$ constant dependent on base thickness and reinforcement. $\alpha_{0}=$ initial stress distribution angle $=38.5^{\circ} . R_{E}=\min \left(\frac{E_{b c}}{E_{s g}}, 5.0\right)=\min \left(\frac{3.48 C B R_{b c}^{0.3}}{C B R_{s g}}, 5.0\right)$. $P=$ tire load $\{\mathrm{kN}\} . r=$ radius of equivalent tire contact area $\{\mathrm{m}\} . \quad s=$ allowable rut depth $\{\mathrm{m}\} . f_{s}=$ reference rut depth $\{\mathrm{m}\} . c_{u}=$ subgrade undrained shear strength $\{\mathrm{kPa}\}$. $N_{c}=$ bearing capacity factor (5.71 for geogrid-reinforced roads). $\xi, \omega$, and $n$ are constants calibrated by Giroud and Han (2004b) using data from unpaved, unreinforced roads $(\xi=0.9, \omega=1.0$, and $n=2.0$ ).

The variable $k$ in Eq. (1) is responsible for describing the contribution of the geosynthetic, as well as contribution of the base thickness and equivalent radius of the applied load $\left[(r / h)^{1.5}\right]$. The general form of the equation to describe $k$ (Eq. (2)), as published by Giroud and Han (2004a,b), was based on the calibration of two biaxial geogrids in terms of the aperture stability modulus $(J)$.

$k=\left(0.96-1.46 J^{2}\right)\left(\frac{r}{h}\right)^{1.5}$

The first step in this process was to isolate the constant $k$ in Eq. (1). The result of this algebraic manipulation (and subsequent substitution of the constant values for $\xi$, $\omega$, and $n$ ) is presented in Eq. (3). The variable $k$ was redefined as $k^{\prime}$ to indicate a back-calculated value, as described below.

$$
\left.k^{\prime}=\left[\frac{h\left[1+0.204\left(R_{E}-1\right)\right]}{1.26\left[\sqrt{\frac{\frac{p}{\pi r^{2}}}{\left(\frac{s}{f_{s}}\right)\left[1-0.9 \exp \left(-\left(\frac{r}{h}\right)^{2}\right)\right] N_{c} c_{u}}}-1\right] r}-1\right] \frac{1}{\log N\left(\frac{r}{h}\right)^{1.5}}\right)
$$

The following material properties of the test sections were used in Eq. (3) to determine $k$ ' for each test section. $h=0.276 \mathrm{~m}$; average thickness of base course layer. $R_{E}=4.8$; average $C B R_{b c}$. field $=20$, average $C B R_{s g}=1.79$. $P=37.63 \mathrm{kN} . \quad r=0.139 \mathrm{~m} . \quad N_{c}=5.71 . \quad c_{u}=62.7 \mathrm{kPa}$. $f_{s}=75 \mathrm{~mm}$.

The single property that varied within the test sections was the number of axle passes of the truck $(N)$ for a particular rut level. The value of $k^{\prime}$ was determined at various levels of rut $(s=38.1 \mathrm{~mm}, 50.8 \mathrm{~mm}, 63.5 \mathrm{~mm}$ and $76.2 \mathrm{~mm}$ ) and axle passes. Because $k^{\prime}$ represents the material property of the geogrid associated with design, it was plotted with respect to the various properties of the geosynthetic, as in the regression analysis previously described above. Similar to that analysis, linear regression was used to fit the data from these comparisons, the results of which are summarized in Fig. 9.

Not surprisingly, a similar pattern of interdependence between $k^{\prime}$ and junction stiffness emerged from these analyses. Therefore, junction stiffness in the cross-machine direction emerged from this analysis as the primary material property related to rutting performance. This does not mean that tensile strength in the cross-machine direction is unimportant, as indicated by the previous regression analyses. Development of the tensile capacity of the geogrid was critically dependent on the ability of the junction to transmit stresses into members oriented in the crossmachine direction. Therefore, materials that have sufficient tensile strength but weak junctions will not perform well. The converse is also true - strong junctions with weak members will also not perform well. Reasons why the aperture stability modulus did not correlate to performance are unknown. The individual slopes of $k^{\prime}$ versus junction stiffness varied as a function of rut, as shown in 


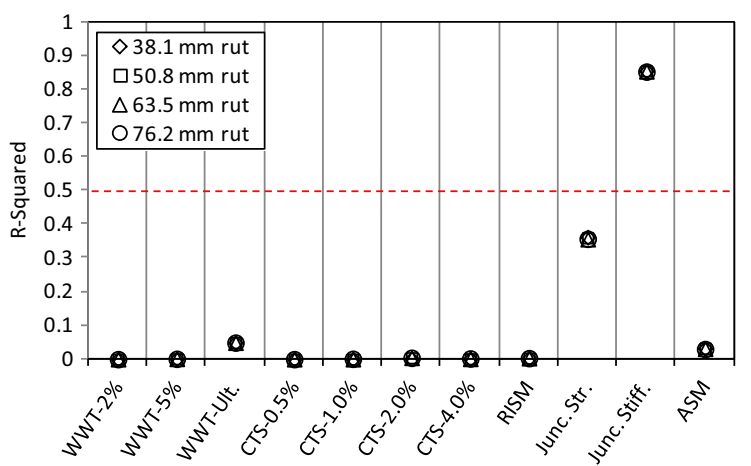

Fig. 9. Regression analysis results for $\mathrm{k}^{\prime}$ with respect to geogrid material properties in the cross-machine direction.

Fig. 10. The information contained in Fig. 10 can be used to determine the value of $k^{\prime}$ based on junction stiffness (in units of $\mathrm{MN} / \mathrm{m} / \mathrm{m}$ ).

To validate the accuracy of this method, Eq. (3) was rearranged in terms of $N$, the number of traffic passes, and the predicted number of passes was determined based on junction stiffnesses of the geogrids used in this project. Values for $k$ ' were determined using the relationships presented in Fig. 10. The predicted values were compared to the actual number of passes to reach various levels of rut, the results of which are shown in Fig. 11. These results indicate that there is good correlation between the predicted and actual values.

The final form of the design equation for geosynthetic reinforced unpaved roadways, based on the development work by Giroud and Han (2004a) and the calibration based on field test sections constructed by Cuelho et al. (2014), is shown in Eq. (4). It should be noted that the base course layer thickness $(h)$ is present on both sides of the equation;

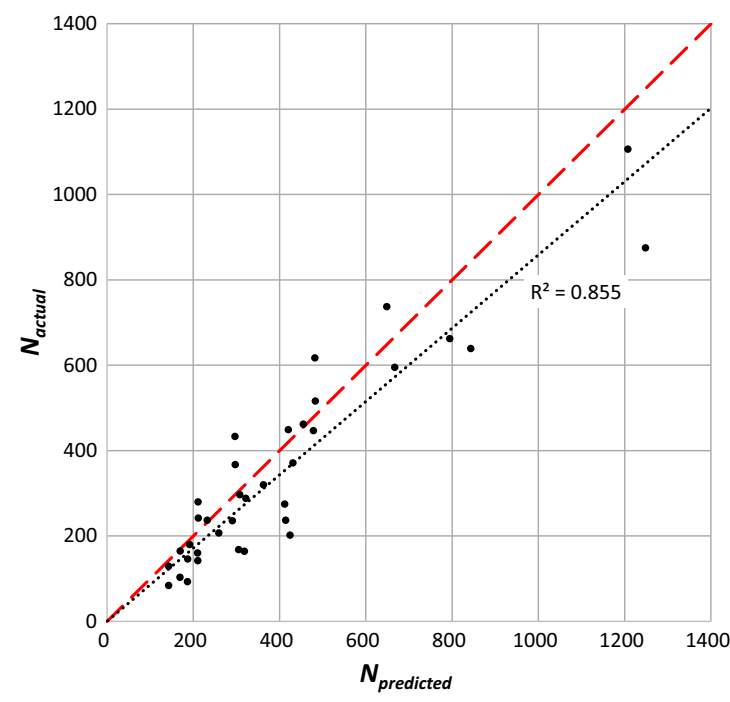

Fig. 11. Comparison of predicted axle passes to actual axle passes.

therefore, an iterative process is necessary to determine a single value of $h$ for a given set of conditions. The variable $k^{\prime}$ is based solely on junction stiffness (ASTM D7737), and can be determined using the relationships presented in Fig. 10. The information contained in Fig. 10 is shown for various levels of expected rut, as indicated by the multiple lines. The regression line is extended to include products with greater junction stiffnesses than the materials used in this study.

$h=\frac{1.26\left[1+k^{\prime}\left(\frac{r}{h}\right)^{1.5} \log N\right]}{1+0.204\left(R_{E}-1\right)}\left[\sqrt{\frac{\frac{P}{\pi r^{2}}}{\left(\frac{s}{f_{s}}\right)\left[1-0.9 \exp \left(-\left(\frac{r}{h}\right)^{2}\right)\right] N_{c} c_{u}}}-1\right] r$

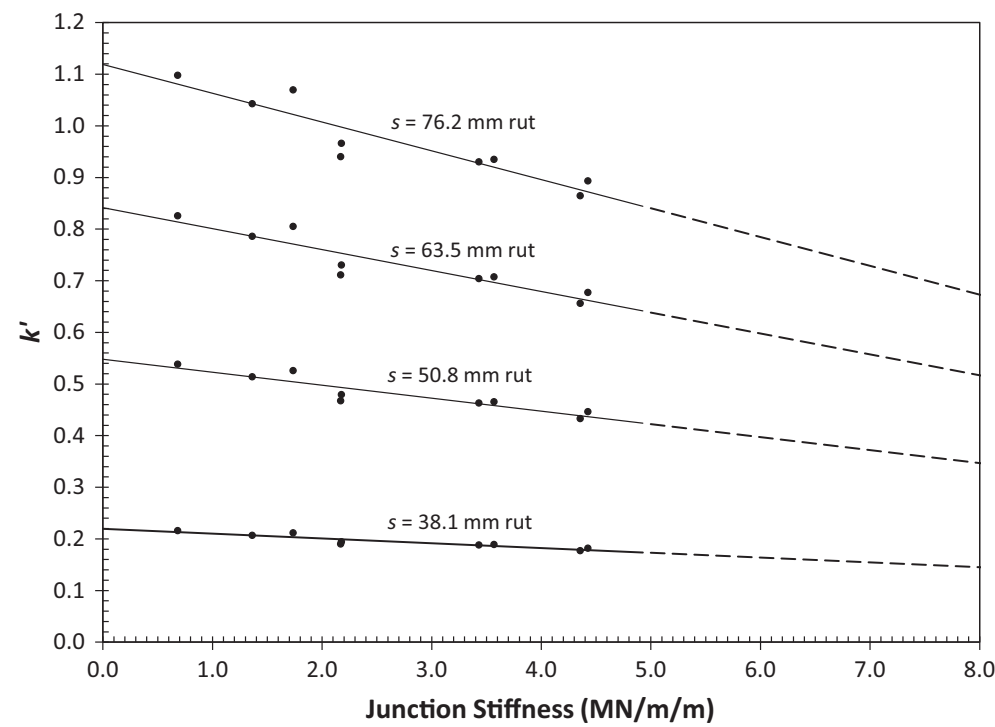

Fig. 10. Junction stiffness versus $\mathrm{k}^{\prime}$ for various levels of rut. 


\section{Summary and conclusions}

Geosynthetics are routinely used to stabilize weak soils in transportation applications; however, deficiencies in the standard design techniques have made widespread adoption of the existing methods slow. In addition, agreement as to which geosynthetic properties are most relevant to subgrade stabilization applications is lacking. A rigorous program was undertaken by researchers at the Western Transportation Institute at Montana State University, and sponsored by the Montana Department of Transportation, to build and traffic multiple test sections containing various types of geosynthetic reinforcement products. The results of this effort were used to better understand which properties are most relevant to subgrade stabilization of unpaved roads, and consequently to update the design methodology to incorporate these material properties.

Test sections were built and trafficked in a large-scale controlled laboratory environment to study the performance of various geosynthetics to stabilize weak subgrades. A comprehensive set of material tests were conducted to more thoroughly evaluate the potential relationship between geosynthetic material properties and the relative performance of the test sections. The results of a regression analysis showed that junction stiffness was the best indicator of performance under these conditions.

The Giroud-Han method is currently the most sophisticated method to design geosynthetic stabilized unpaved roads; however, calibration of this method to date is based on very limited data. Performance data from the full-scale field tests built as part of this research effort were used to calibrate the Giroud-Han design equation. Geogrid junction stiffness in the cross-machine direction was the primary indicator of performance in these test sections and was therefore used as the material property to calibrate the design equation. Nevertheless, tensile strength in the cross-machine direction is also important, as indicated by the regression analyses. Development of the tensile capacity of the geogrid is critically dependent on the ability of the junction to transmit stresses into members oriented in the cross-machine direction. Correlations between predicted axle passes and actual axle passes indicated good predictions using the calibrated equation. The newly calibrated design equation presented herein replaces aperture stability modulus with junction stiffness in the crossmachine direction to describe the contribution of the geogrid.

\section{Acknowledgements}

Financial support for this pooled-fund study lead by Montana Department of Transportation was generously provided by the following United States departments of transportation (listed in alphabetical order) - Idaho, Montana, New York, Ohio, Oklahoma, Oregon, South Dakota, Texas and Wyoming. Geosynthetic materials were charitably donated by Colbond, Huesker, NAUE, Propex, Synteen and TenCate.

\section{References}

ASTM Standard D1883. Standard test method for california bearing ratio (CBR) of laboratory-compacted soils. West Conshohocken, PA: ASTM International; 2007. www.astm.org.

ASTM Standard D2487. Standard practice for classification of soils for engineering purposes (unified soil classification system). West Conshohocken, PA: ASTM International; 2011. www.astm.org.

ASTM Standard D4595. Standard test method for tensile properties of geotextiles by the wide-width strip method. West Conshohocken, PA: ASTM International; 2011. www.astm.org.

ASTM Standard D4632. Standard test method for grab breaking load and elongation of geotextiles. West Conshohocken, PA: ASTM International; 2008. www.astm.org.

ASTM Standard D4751. Standard test method for determining apparent opening size of a geotextile. West Conshohocken, PA: ASTM International; 2004. www.astm.org.

ASTM Standard D6637. Standard test method for determining tensile properties of geogrids by the single or multi-rib tensile method. West Conshohocken, PA: ASTM International; 2011. www.astm.org.

ASTM Standard D7499. Standard test method for measuring geosynthetic-soil resilient interface shear stiffness. West Conshohocken, PA: ASTM International; 2009. www.astm.org.

Standard test methods for determining small-strain tensile properties of geogrids and geotextiles by in-air cyclic tension tests. West Conshohocken, PA: ASTM International; 2010. www.astm.org.

ASTM Standard D7737. Standard test method for individual geogrid junction strength. West Conshohocken, PA: ASTM International; 2011. www.astm.org.

Benson CH, Edil TB, Tanyu BF, Kim W-H. Equivalency of crushed rock with industrial by-products and geosynthetic-reinforced aggregates used for working platforms during pavement construction. Wisconsin Highway Research Program, Final Report No. 0092-00-12; 2005. p. 100.

Cuelho E, Perkins S, Field investigation of geosynthetics used for subgrade stabilization. Final Report to the Montana Department of Transportation, FHWA/MT-09-003/8193; 2009. p. 140.

Cuelho E, Perkins S, Morris Z. Relative operational performance of geosynthetics used as subgrade stabilization. Final Report to the Montana Department of Transportation, FHWA/MT-14-002/7712251; 2014. p. 328.

Edil TB, Benson CH, Senol A, Bin-Shafique MS, Tanyu BF, Kim W-H, Field evaluation of construction alternatives for roadway over soft subgrade. Wisconsin Highway Research Program, Interim Report; 2002. p. 65.

Fannin RJ, Sigurdsson O. Field observations on stabilization of unpaved roads with geosynthetics. J Geotechn Eng 1996;122(7):544-53.

Gabr M. Cyclic plate loading tests on geogrid reinforced roads. Research Report to Tensar Earth Technologies Inc., NC State Univ.; 2001. p. 43.

Giroud JP, Han J. Design method for geogrid-reinforced unpaved roads. Part I - development of design method. J Geotechn Geoenviron Eng 2004a;130(8):775-86.

Giroud JP, Han J. Design method for geogrid-reinforced unpaved roads. Part II - calibration and applications. J Geotechn Geoenviron Eng 2004b;130(8):787-97.

Giroud JP, Noiray L. Geotextile-reinforced unpaved road design. J Geotechn Eng 1981;107(9):1233-54.

Giroud JP, Ah-Line C, Bonaparte R. Design of unpaved roads and trafficked areas with geogrids. In: Proceedings of a conference sponsored by the science and engineering research council, polymer grid reinforcement. London: Thomas Telford Ltd; 1985. p. 116-27.

Haliburton TA, Lawmaster JD, McGuffey VC. Use of engineering fabrics in transportation related applications. Federal Highway Administration; 1981. FHWA DTFH61-80-C-00094.

Hammitt GM. Thickness requirement for unsurfaced roads and airfields, bare base support, project 3782-65. CE, Vicksburg, Miss: U.S. Army Engineer Waterways Experiment Station; 1970. p. 139. Technical Rep. S-70-5.

Holtz RD, Christopher BR, Berg RR. Geosynthetic design and construction guidelines. Washington DC: U.S. Department of Transportation, Federal Highway Administration; 2008. p. 592. Report No. FHWANHI-07-092.

Hufenus R, Rueegger R, Banjac R, Mayor P, Springman SM, Bronnimann R. Full-scale field tests on geosynthetic reinforced unpaved roads on soft subgrade. Geotext Geomembr 2006;24(1):21-37.

Kinney T. Standard test method for determining the "aperture stability modulus" of a geogrid. Seattle: Shannon \& Wilson Inc.; 2000.

Leng J. Characteristics and behavior of geogrid-reinforced aggregate under cyclic load (Ph.D. thesis). North Carolina State University; 2002. 
Maxwell S, Kim W-H, Edil TB, Benson CH. Geosynthetics in stabilizing soft subgrades with breaker run. Wisconsin Highway Research Program. Final Report No. 0092-45-15; 2005. p. 88.

Perkins SW. Evaluation of geosynthetic reinforced flexible pavement systems using two pavement test facilities. Montana Department of Transportation. Final Report No. FHWA/MT-02-008/20040; 2002. p. 136.

Perkins SW, Bowders JJ, Christopher BR, Berg RR. Geosyntheticreinforcement for pavement systems: US perspectives. In: Proceedings: Geo-Frontiers 2005, ASCE Geotechnical Special Publications 130-142. Reston, VA: American Society of Civil Engineers; 2005. p. 3039-63.

Santoni RL, Smith CJ, Tingle JS, Webster SL. Expedient road construction over soft soils. U.S. Army Corps of Engineers; 2001. p. 107. Final Report No. ERDC/GSL TR-01-7.

Steward J, Williamson R, Mohney J. Guidelines for use of fabrics in construction and maintenance of low-volume roads. USDA, Forest Service, Portland, OR. Also Reprinted as Report No. FHWA-TS-78-205, Federal Highway Administration, Washington, D.C; 1977.

Tingle JS, Webster SL. Corps of engineers design of geosyntheticreinforced unpaved roads. Transp Res Rec 2003;1849:193-201.

United States Corps of Engineers. Use of geogrids in pavement construction, ETL 1110-1-189. Washington, D.C.: Department of the Army, U.S. Army Corps of Engineers; 2003. p. 37.

Watn A, Eiksund G, Jenner C, Rathmayer H. Geosynthetic reinforcement for pavement systems: European perspectives. In: Proceedings: GeoFrontiers 2005, ASCE geotechnical special publications 130142. Reston, VA: American Society of Civil Engineers; 2005. p. 3019-37. 